\title{
Residual stresses in high-strength steel welded square box sections
}

Balázs Somodi MSC

PhD Student, Department of Structural Engineering, Budapest University of Technology and Economics, Budapest, Hungary (corresponding author: somodi.balazs@epito.bme.hu)

\section{Dénes Kollár MSc}

PhD Student, Department of Structural Engineering, Budapest University of Technology and Economics, Budapest, Hungary

\section{Balázs Kövesdi PhD}

Associate Professor, Department of Structural Engineering,

Budapest University of Technology and Economics, Budapest, Hungary

\section{János Néző PhD}

Senior Researcher, Department of Structural Engineering, Budapest

University of Technology and Economics, Budapest, Hungary

László Dunai DSC

Professor, Department of Structural Engineering, Budapest University of Technology and Economics, Budapest, Hungary

Previous research has shown that the residual stresses in high-strength steel (HSS) members can be smaller than those in normal-strength steel structures. To investigate the residual stress distribution in HSS structures, a complex experimental and numerical research programme was carried out on welded square box sections at the Budapest University of Technology and Economics. The test specimens were obtained from three different manufacturers using six different steel grades (S235, S355, S420, S460, S500 and S960). Parallel to the laboratory tests, the effect of the welding process on residual stresses was also studied using a numerical welding simulation technique. The shape and intensity of the residual stress pattern on square box section members were also determined by numerical simulations and compared with the test results. The observed tendencies in the tests and numerical simulations were analysed with respect to the effect of yield strength and section dimensions on the residual stress distribution and magnitude.

\section{Notation}

$a \quad$ half width of heat source model

$B \quad$ penetration in double ellipsoidal heat source model

$b \quad$ outer width of section

$b_{\text {lok }} \quad$ inner width of section $\left(b_{\text {lok }}=b-2 t\right)$

$c_{\mathrm{f}} \quad$ length of the front ellipsoid

$f_{\mathrm{y}} \quad$ yield strength

$f_{\mathrm{u}} \quad$ ultimate strength

I current

$L_{\mathrm{c}} \quad$ width of compression zone

$Q \quad$ heat input

$q \quad$ heat density of the front and rear ellipsoid

$q_{\mathrm{f}} \quad$ heat density of the front ellipsoid

$t \quad$ thickness of section

$U$ voltage

$\varepsilon \quad$ emissivity coefficient

$\eta \quad$ welding efficiency

$\sigma_{\mathrm{rc}} \quad$ compressive residual stress (CRS)

$\sigma_{\mathrm{rt}} \quad$ tensile residual stress (TRS)

\section{Introduction}

Previous research results have shown that residual stress has a smaller influence in high-strength steel structures (HSS) than in normal-strength steel (NSS) structures. The general aim of research programme described in this paper was to investigate the residual stress distribution and its extreme values in HSS welded square hollow section members and NSS members. The research results presented are part of the Ruoste project (Rules on high-strength steel) (RFCS, 2016) and the SteelBeam R\&D project (BME, 2016).
Previous residual stress measurements available in the international literature dealing with HSS welded box sections are limited. The applicability of these measurements is also limited and the test results are not always in harmony. Although residual stress models for NSS sections have been extensively investigated in the past and design models have been developed, the applicability of these residual stress models are questionable in case of HSS structures because of the following.

- The material properties and manufacturing process of HSS sections are different from those of NSS sections.

- The magnitude of compressive residual stresses (CRSs) can be lower for HSS members (related to the yield strength $f_{\mathrm{y}}$ ) than for NSS structures.

- Several current residual stress models, such as those in use in Europe (ECCS, 1976), China (CDSSC, 2003) and the USA (Galambos, 1998), do not take the cross-section geometry into account or simplify its effect. However, some previous test results have shown that residual stresses strongly depend on the width-to-thickness ratio $(b / t)$ of the investigated cross-section (Ban et al., 2013a).

These factors indicate that investigation of the residual stress distribution in welded HSS box section members is important. The research presented in this paper focused on the results of residual stress measurements carried out at Budapest University of Technology and Economics (BME) in 2014-2016. The aim of the investigation was to measure the residual stresses in test specimens to determine the dependency of extreme values (maximum tensile and average compressive stresses) and the residual stress pattern on the steel grade and 


\section{Offprint provided courtesy of www.icevirtuallibrary.com Author copy for personal use, not for distribution}

the $b / t$ ratio. The experimental programme was extended by numerically simulating the welding process in order to investigate the effect of different geometrical parameters and steel grades on the residual stress pattern over a large parameter range. This paper summarises the key findings related to the residual stress distribution of HSS welded box section members based on laboratory tests and numerical simulations. The research programme is unique compared with previous research because it investigated a wide range of steel grades (S235-S960) using the same cross-sectional geometries produced by similar manufacturing process (butt welds with the same welding process and heat input parameters) and using the same measuring method (sectioning technique). This method made it possible to reduce the effect of differences in manufacturing processes on the test results and provided a good platform for comparison.

\section{Literature review}

The first experimental research programme on this topic was executed by Rasmussen and Hancock (1992) who investigated different stub columns made of S650 and S690 steel grades. For all the analysed cross-sections, residual stress measurements and buckling tests were carried out. Ban et al. investigated the residual stresses of six S460 (Ban et al. 2013a) and S960 (Ban et al. 2013b) welded box section members. Longitudinal residual stress measurements were executed using the sectioning technique. Based on the test results, Ban et al. concluded that the CRS is significantly influenced by the cross-section geometries of wall thickness $(t)$ and the widthto-thickness $(b / t)$ ratio. According to the models proposed by Ban et al., the magnitude of CRS $\left(\sigma_{\mathrm{rc}}\right)$ can be determined using Equation 1 and Equation 2 for S460 and S960 steel grades, respectively.

1. $\sigma_{\mathrm{rc}, \mathrm{S} 460}=-10-1500 \frac{1}{b / t}-550 \frac{1}{t}$

2. $\sigma_{\mathrm{rc}, \mathrm{S} 960}=-95-1450 \frac{1}{b / t}-270 \frac{1}{t}$

Wang et al. (2012) investigated the residual stress distribution of three Q460 steel box sections using both sectioning and hole-drilling techniques. Based on the test results, the authors concluded that the CRS/yield strength ratio $\left(\sigma_{\mathrm{rc}} / f_{\mathrm{y}}\right)$ for HSS members was significantly smaller than for NSS members. The test results also showed that the $b / t$ ratio has a significant influence on both the tensile residual stress (TRS) and the CRS. Clarin (2004) and Clarin and Lagerqvist (2005) investigated the residual stress distribution of three box section specimens made of three different steel grades (Domex 420, Weldox 700, Weldox 1100). Pavlovčič et al. (2012) measured the residual stress distribution of a welded box section made of S355 steel grade. Two welded box sections made of S690 HSS were tested by Nishino et al. (1967). Six welded box sections made of S690 and S460 steel grades are tested by Usami and
Fukumoto (1982, 1984). Uy (2001) measured the residual stresses of three box section columns. Based on the literature review, it can be concluded that the measured shape of the residual stress pattern in square box section members is commonly accepted by researchers. It is also commonly known that the outer and inner residual stresses are nearly equal, which means that mainly membrane residual stresses exist in the members. In the corner zones (welded regions) there are always high TRSs, which can reach or even exceed the yield strength. In the middle part of the plates there is a moderate CRS distribution and its value is always less than the TRS in the corner zones. Therefore, the compressed part of the crosssection is always larger than the tension zone. However, regarding the magnitude of the extreme values of TRSs and CRSs there are contradicting conclusions in the international literature. Several models give the TRS and CRS as a function of the yield strength multiplied by a constant factor. However, the major conclusions of previous investigations showed that, with the use of higher steel grades, the multiplier of the yield strength in the case of CRS should also be dependent on the yield strength, so the relationship is not linear. On the other hand, several test results have shown that the maximum CRS depends strongly on the $b / t$ ratio. Several results have shown that the dependency on $b / t$ is different for different plate thicknesses (Ban et al., 2013a), other results and models do not show this dependency on plate thickness (ECCS, 1976) and several test programmes have only dealt with one plate thickness (Rasmussen and Hancock, 1992; Wang et al., 2012). Considering these test results, the dependency on plate thicknesses cannot be established. There is therefore a need to harmonise all the previous test results and collect them into one design residual stress model. However, the focus of the current paper is on clarification of the influential effects on these parameters $\left(b / t, t, f_{\mathrm{y}}\right)$ for HSS members rather than presenting a general residual stress model.

\section{Results of laboratory tests}

\subsection{Test programme and measurement method}

Within the experimental research programme the residual stress distributions of 21 welded box section specimens were investigated in tests carried out in the Structural Laboratory of the BME Department of Structural Engineering. The box sections studied were of six different steel grades and nine different cross-section geometries. Different cross-sections were investigated to study the effect of geometry and $b / t$ ratio on the residual stress distribution. Specific cross-sections manufactured from different steel grades but with the same geometry were used to study the effect of the steel grade. Table 1 summarises the geometries and the material properties of the 21 investigated test specimens. The material properties (yield and ultimate strengths) of all the test specimens were determined from coupon tests and the measured material properties were considered in the evaluation process. All the specimens were tested using the sectioning technique, with sectioning 
Table 1. Investigated cross-sections

\begin{tabular}{|c|c|c|c|c|c|c|c|c|}
\hline Specimen & $b: \mathbf{m m}$ & $t: \mathrm{mm}$ & $b_{\text {lok }} / t$ & $f_{\mathrm{y}}: \mathrm{MPa}$ & $f_{\mathrm{u}}: \mathrm{MPa}$ & $\sigma_{\mathrm{rc}}: \mathrm{MPa}$ & $\sigma_{\mathrm{rt}}: \mathrm{MPa}$ & $L_{c} / b$ \\
\hline \multicolumn{9}{|l|}{ Steel grade S235 } \\
\hline W2-80 × 5 & 80 & 5 & $14 \cdot 0$ & 327 & 469 & -162 & 347 & 0.61 \\
\hline$W 2-120 \times 6$ & 120 & 6 & $18 \cdot 0$ & 324 & 451 & -182 & 365 & 0.66 \\
\hline$W 2-150 \times 6$ & 150 & 6 & $23 \cdot 0$ & 325 & 482 & -160 & 334 & 0.69 \\
\hline W2-180 × 8_A & 180 & 8 & $20 \cdot 5$ & 318 & 445 & -134 & 390 & 0.72 \\
\hline W2-180 × 8_C & 180 & 8 & $20 \cdot 5$ & 320 & 448 & -91 & 413 & 0.72 \\
\hline \multicolumn{9}{|l|}{ Steel grade S355 } \\
\hline W3-80 × 5 & 80 & 5 & $14 \cdot 0$ & 404 & 568 & -185 & 396 & 0.59 \\
\hline W3-120 × 6 & 120 & 6 & $18 \cdot 0$ & 414 & 571 & -111 & 414 & 0.70 \\
\hline W3-150 × 6 & 150 & 6 & $23 \cdot 0$ & 391 & 516 & -150 & 440 & 0.70 \\
\hline \multicolumn{9}{|l|}{ Steel grade $\mathbf{S 4 2 0}$} \\
\hline$W 4-180 \times 8$ & 180 & 8 & $20 \cdot 5$ & 451 & 530 & -109 & 352 & 0.76 \\
\hline \multicolumn{9}{|l|}{ Steel grade $\$ 460$} \\
\hline W4-80 × 5 & 80 & 5 & $14 \cdot 0$ & 506 & 574 & -176 & 431 & 0.62 \\
\hline W4-120 × 6 & 120 & 6 & $18 \cdot 0$ & 488 & 540 & -121 & 568 & 0.70 \\
\hline W4-150 × 6 & 150 & 6 & $23 \cdot 0$ & 479 & 542 & -130 & 526 & 0.75 \\
\hline \multicolumn{9}{|l|}{ Steel grade $\mathbf{5} 500$} \\
\hline W5-120 ×6_R & 120 & 6 & $18 \cdot 0$ & 546 & 636 & -104 & 473 & 0.80 \\
\hline W5-150 × 6_R & 150 & 6 & $23 \cdot 0$ & 546 & 636 & -127 & 420 & 0.72 \\
\hline W5-195 × 6_R & 195 & 6 & $30 \cdot 5$ & 563 & 636 & -169 & 517 & 0.70 \\
\hline W5-250 × 4_S & 250 & 4 & $60 \cdot 5$ & 624 & 692 & -109 & 527 & 0.84 \\
\hline \multicolumn{9}{|l|}{ Steel grade $\$ 960$} \\
\hline W9-120 × 6_S & 120 & 6 & $18 \cdot 0$ & 1005 & 1047 & -76 & 931 & 0.84 \\
\hline W9-120 × 6_R & 120 & 6 & $18 \cdot 0$ & 992 & 1084 & -124 & 793 & 0.83 \\
\hline W9-170 ×6_R & 170 & 6 & $26 \cdot 3$ & 992 & 1084 & -104 & 889 & 0.78 \\
\hline W9-220 × 6_R & 220 & 6 & $34 \cdot 7$ & 992 & 1084 & -145 & 840 & 0.72 \\
\hline W9-250 × 6_R & 250 & 6 & $39 \cdot 7$ & 992 & 1084 & -71 & 528 & 0.69 \\
\hline
\end{tabular}

accomplished by sawing and applying appropriate cooling with water.

\subsection{Test results}

The residual stress patterns for all the test specimens were determined using electric strain gauges placed at one crosssection of the specimen around the whole box section. Two of these patterns are shown in Figure 1. High TRSs were measured in the corner zones and moderate CRSs were measured in the middle part of the plates. The patterns obtained for all specimens were evaluated. Three values were determined for each investigated side of the cross-section

- the maximum tensile stresses in the corner zone $\left(\sigma_{\mathrm{rt}}\right)$

average compressive stresses in the middle zone of the plates $\left(\sigma_{\text {rc }}\right)$

- length of the compressed plate width $\left(L_{\mathrm{c}}\right)$.

It was observed that the residual stresses in the inner and outer surfaces were almost equal, meaning that there were only negligible bending residual stresses in the plates. The membrane residual stresses were determined from the average of the measured values on the inner and outer surfaces. The results showed that the TRSs in the corner zones were significantly larger for higher steel grades (420-931 MPa) than for the NSS specimens (334-568 MPa), which indicates their dependency on yield strength. The average CRSs were determined for all specimens on both sides by dividing the numerical integral of the residual stress pattern on the compression side by the width of the compression zone. The measured maximum TRSs, the average CRSs and the width of the compression zones (normalised by plate width) are summarised in Table 1 for all the test specimens.

\subsection{Observed tendencies for the residual stress pattern of HSS members}

For welded NSS box sections it is commonly accepted that the TRSs in the corner region are equal to the yield strength, the only difference between the various design models being the consideration of the tension zone width. Previous tests on HSS members (Clarin, 2004; Clarin and Lagerqvist, 2005) showed that the maximum tensile stress for HSS members can be significantly lower than the yield strength, indicating a dependency of maximum tensile stress on the steel grade. Therefore, the test results obtained in this work were evaluated as a function of the measured yield strength. Figure 2 shows the maximum TRSs (normalised by the actual yield strength) as a function of the measured yield strength. The results show that the maximum TRS reached or at least approached the nominal yield strength for S500 and lower strength grades. For the S960 specimens, the maximum measured TRSs almost 


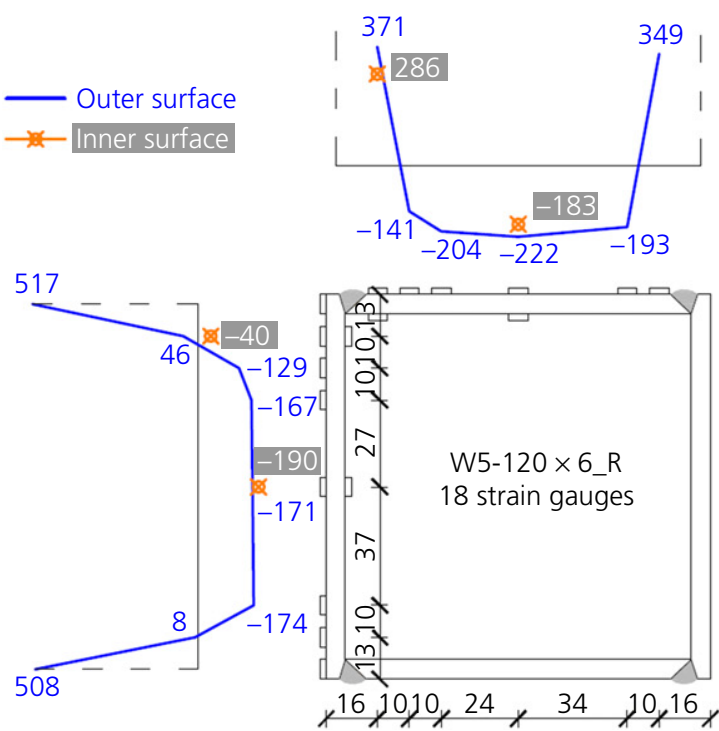

(a)
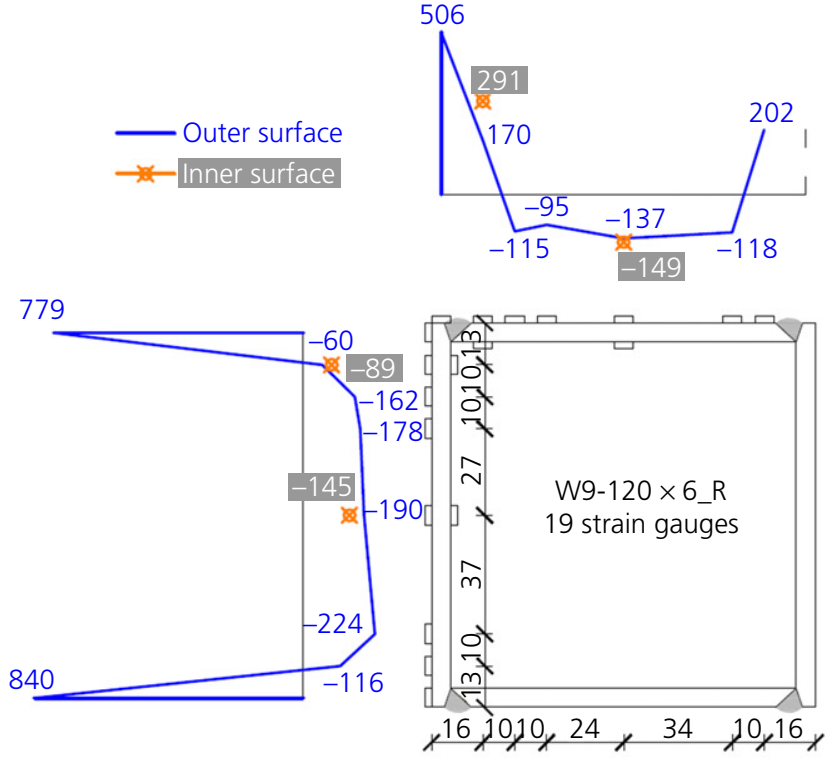

(b)

Figure 1. Residual stresses (in MPa) and positions of strain gauges (dimensions in mm) of specimens (a) W5-120 $\times 6$ _R and (b) W9-120 ×6_R

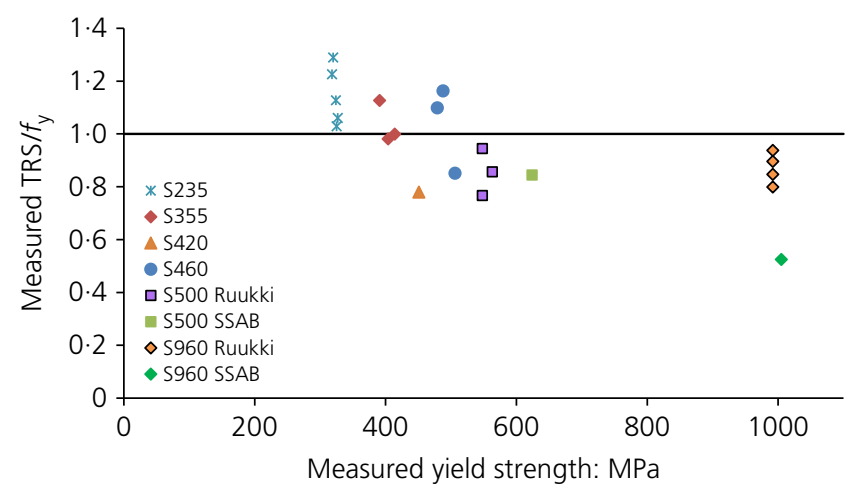

Figure 2. Measured TRSs in the corner zones depending on the yield strength

reached the yield strength but, for several test specimens, the measured residual stress did not reach the yield strength.

Figure 2 shows that there was significant scatter in the measurements for all steel grades, but the scatter was similar for the NSS and HSS materials. The results show good agreement with the database collected by Clarin (2004) and Clarin and Lagerqvist (2005). It should be mentioned here that the measurement of TRSs in HSS materials is much more difficult than for NSS structures because the slope of the residual stress diagram in the corner zone is significantly larger. This results in a larger effect of the strain gauge position and in the averaging of the strain gauges at the measured maximum.
Considering the measurement results, the authors suggest taking the TRS as equal to the yield strength for all the analysed steel grades (S235-S960) in the corner zone.

The test results regarding the CRSs showed that the compressive stress can be considered constant in the compression zone. Previous works in the international literature have stated that CRSs can be different for different $b / t$ ratios and for different steel grades. Therefore, all the CRS results were evaluated as a function of the yield strength $\left(f_{\mathrm{y}}\right)$ and the $b / t$ ratio, as shown in Figures 3-4. The figures show that the average CRS was independent of the steel grade, but strongly depended on the $b / t$ ratio and the plate thickness $(t)$. All the collected test results, together with test results found in the literature, are shown in Figure 4 depending on the $t / b$ ratio and separated for different plate thicknesses. It should be noted that the ratio $t / b$ was used instead of $b / t$, since the observed relationships were almost linear using this ratio. The slopes of the lines representing different plate thicknesses in Figure 4 are significantly different, which shows that the CRSs do not depend only on the $b / t$ ratio of the investigated section, but the plate thickness also has a significant effect.

\section{Results of numerical simulations}

\subsection{Research aims and simulation strategy}

Because the scatter in the test results was relatively large, the research programme was extended using numerical simulations to investigate the residual stress patterns in welded square box sections. The aims of the investigations were to verify $(a)$ the 


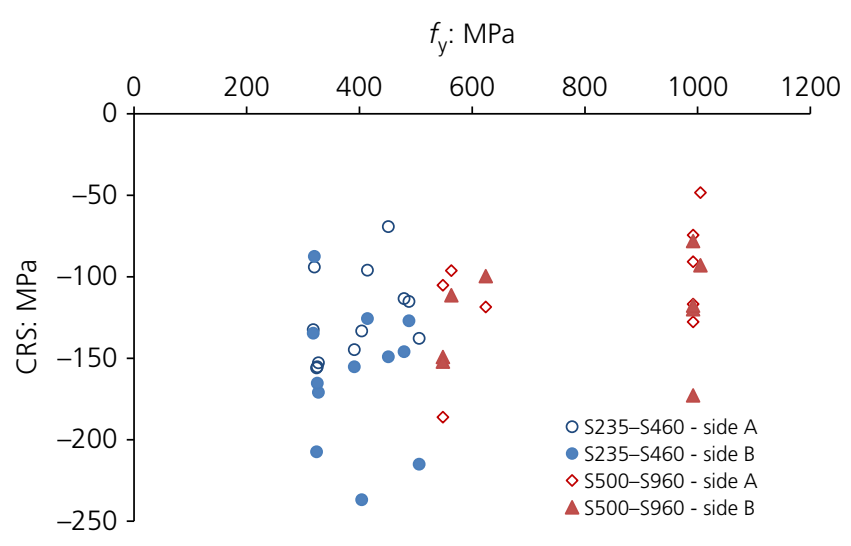

Figure 3. Average CRSs depending on yield strength

numerical model and $(b)$ the observed tendencies based on the test results of residual stress patterns of HSS members. The tendencies observed in the tests to be confirmed by the numerical investigations were the following.

- CRSs are highly influenced by the $b / t$ ratio of the cross-section.

- The effect of $b / t$ on the CRSs depends on the plate thickness $(t)$.

- CRS magnitudes are independent of yield strength.

- Maximum TRSs are equal to the yield strength for all the steel grades analysed.

Numerical simulation for the virtual fabrication of welded specimens was carried out using the Ansys 14.5 finiteelement program (Ansys, 2013). The welding process is a complex thermo-mechanical phenomenon that requires multidisciplinary knowledge. In the current research programme uncoupled thermo-mechanical analyses were carried out to simulate the welding process of the investigated test specimens. Several thermal measurements were taken during the manufacture of the investigated specimens and the applied welding parameters were used in the numerical model. Using the verified model, parametric studies were carried out to investigate the effect of $b / t, t$ and $f_{\mathrm{y}}$ on the residual stress pattern. The maximum applied plate thickness was $8 \mathrm{~mm}$ in the laboratory tests, which was extended in the numerical parametric study. Six different plate thicknesses were included in the numerical study $(4,5,6,8,12$ and $16 \mathrm{~mm})$ for the same plate width (120 mm). Box sections with b/t ratios of 15, 22.5, 30, 37.5 and 45 were studied. Both HSSs and NSSs were included in the numerical simulation process, through the use of five different steel grades (S235, S355, S460, S700 and S960). A total of 150 numerical simulations considering different plate thicknesses, $b / t$ ratios and yield strengths was thus executed.

\subsection{Numerical model and analysis method}

An uncoupled thermo-mechanical analysis was developed to model the welding process (i.e. the thermal and mechanical behaviours of the structure were separated in the numerical simulation). Shell elements and solid elements were combined in the finite-element model to increase the time efficiency of the simulation. The heat-affected zone and the surrounding region of the weld passes featuring high thermal gradients were modelled using solid elements. A dense mesh was used near the butt welds at the corners while the mesh of the shell zones was coarser. The model used eight-node solid elements (Solid70/Solid185) and four-node shell elements (Shell131/Shell181). The thermal analysis included the generated heat and the temperature distribution caused by the heat source function. The applied numerical model is shown in Figure 5. Arc welded specimens were investigated and the double ellipsoidal heat source model of Goldak and Akhlaghi (2005) (Figure 6) was applied. This approximation has several

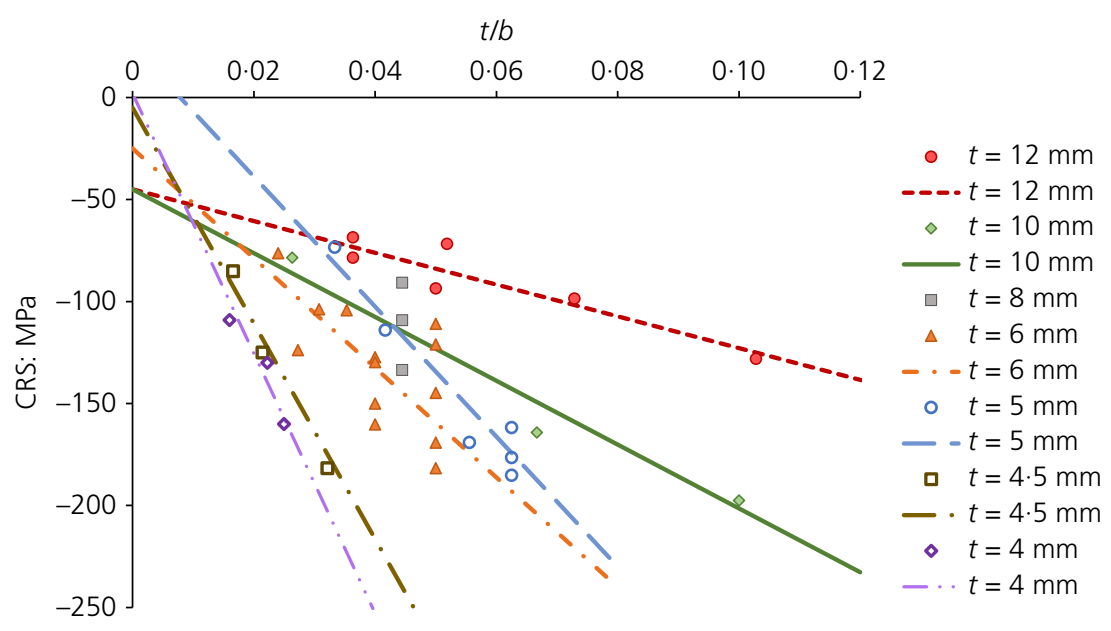




\section{Offprint provided courtesy of www.icevirtuallibrary.com Author copy for personal use, not for distribution}
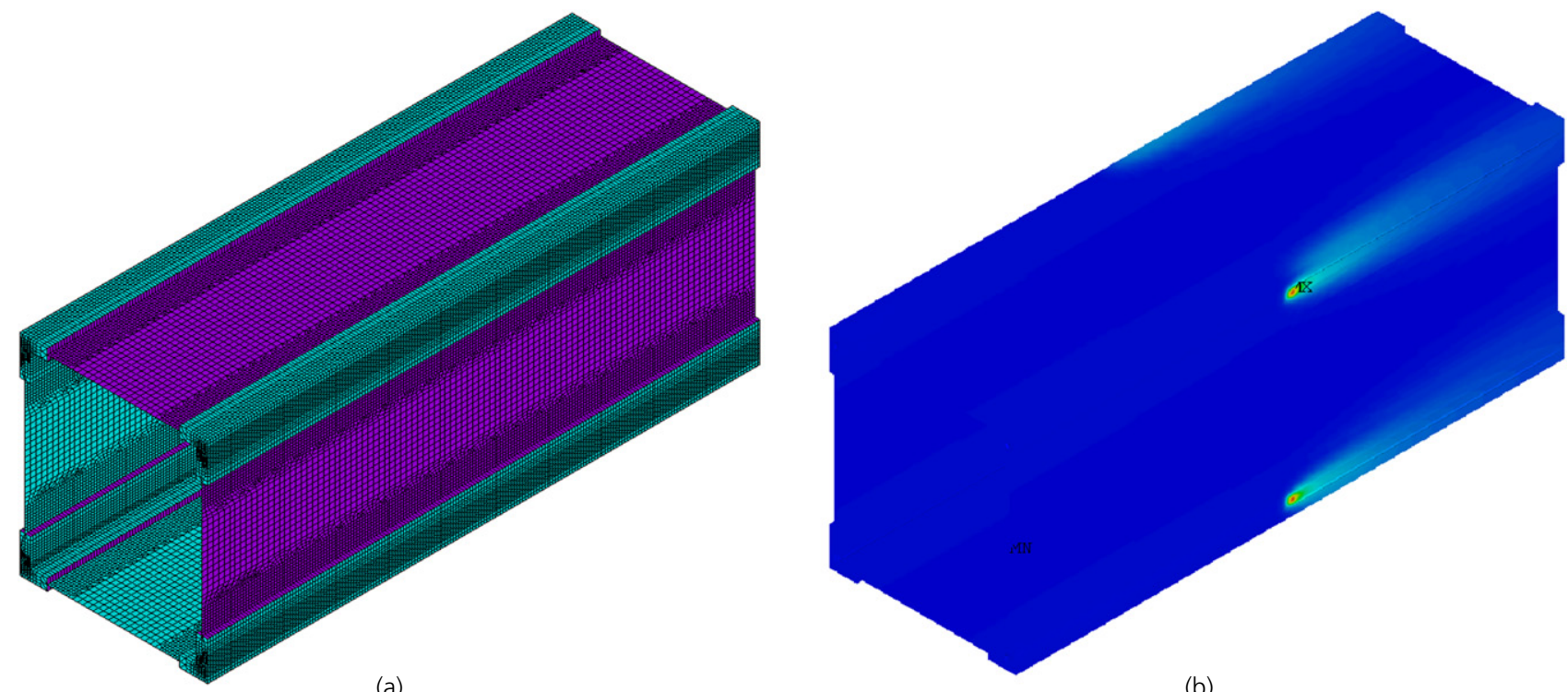

(a)

(b)

Figure 5. (a) Combined shell-solid finite-element model. (b) Moving heat source during simultaneous welding

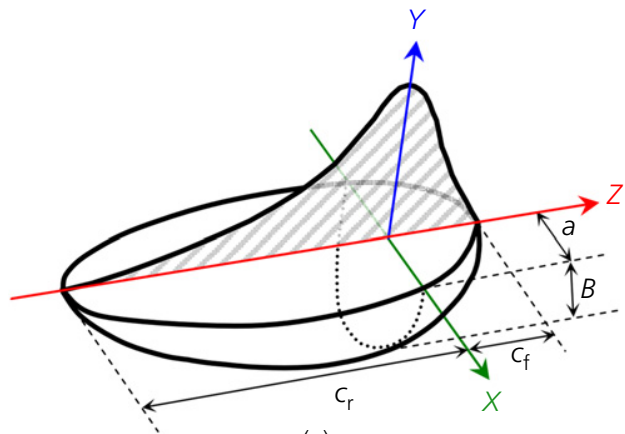

(a)

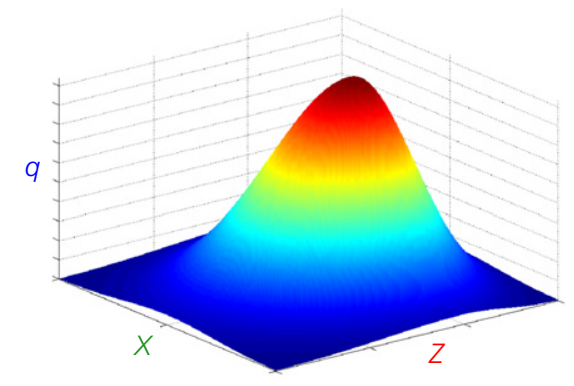

(b)

Figure 6. (a) Geometrical parameters (Naeem Ullah, 2009). (b) Heat density distribution of the double ellipsoidal heat source model (Goldak and Akhlaghi, 2005)

advantages: $(a)$ the size of the front and rear ellipsoids can be calibrated and fitted separately and $(b)$ it can be applied to simulate deep penetration welding. The heat input is given by Equation 3, where $\eta$ is the welding efficiency, $U$ is voltage and $I$ is current

\section{3. $Q=\eta U I$}

The heat density of the double ellipsoidal heat source model (Goldak and Akhlaghi, 2005) is given by

4. $\quad q_{\mathrm{f}}(x, y, z)=Q_{0, \mathrm{f}} \mathrm{e}^{\left[-3\left(x^{2} / a^{2}\right)\right]} \mathrm{e}^{\left[-3\left(y^{2} / B^{2}\right)\right]} \mathrm{e}^{\left[-3\left(z^{2} / c_{\mathrm{f}}^{2}\right)\right]}$

where $q_{\mathrm{f}}$ is the heat density of the front ellipsoid, $a$ is the half width of the heat source model, $B$ is the penetration and $c_{\mathrm{f}}$ is the length of the front ellipsoid.
Generally the parameter $c_{\mathrm{r}}$ (see Figure 6) is twice as long as $c_{\mathrm{f}}$ to avoid a break in continuity in the heat density distribution. The heat source model definition for the ellipsoid is done by changing the indices according to Bradac (2013). $Q_{0, \mathrm{f}}$ and $Q_{0, \mathrm{r}}$ have to be calibrated during the thermal analysis to ensure that the transmitted heat input is equal to $Q$ given by Equation 3 in all time steps when the heat source is applied to the specimen. A detailed description of this heat source is given by Bradac (2013). The initial temperature of the specimen and the ambient temperature were defined as $20^{\circ} \mathrm{C}$ during the thermal analysis. The heat transfer phenomenon is divided into two parts, convection and radiation, and heat transfer can be modelled in different ways in numerical models. In the current case, surface loads acting on nodes were applied. The convective heat transfer coefficient was taken as $25 \mathrm{~W} /\left(\mathrm{m}^{2} \mathrm{~K}\right)$ and the emissivity coefficient $(\varepsilon)$ was assumed to 


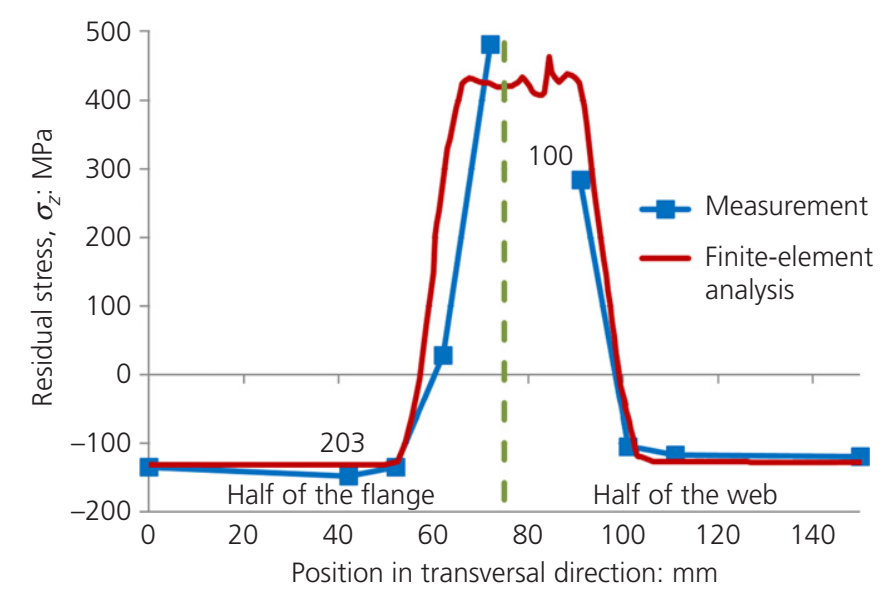

(a)

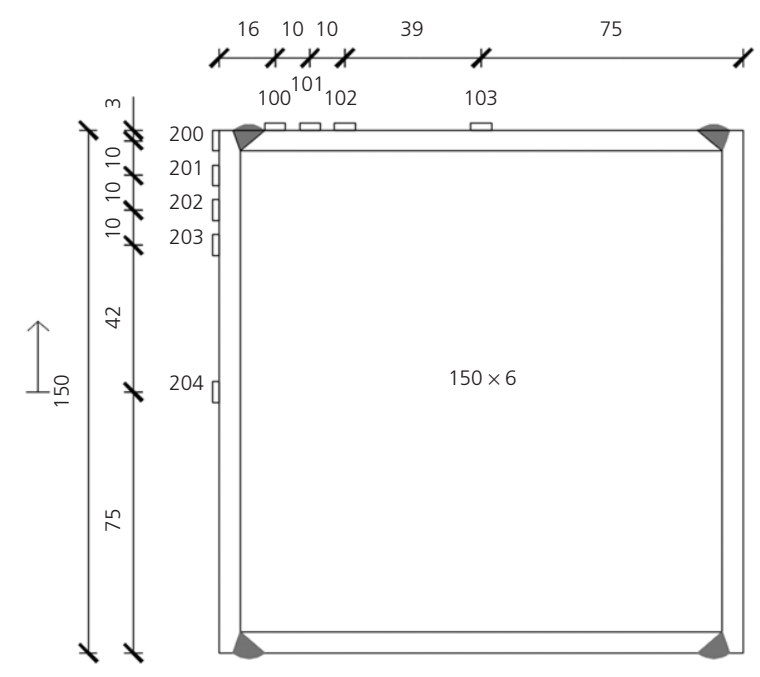

(b)

Figure 7. (a) Comparison of measured and computed residual stresses. (b) Positions of strain gauges (dimensions in mm)

be $0 \cdot 8$. In the mechanical analysis, the structure was modelled as a statically determinate system during welding. This is a time-saving technique to simplify large models by defining a plane symmetry.

The applied thermal and mechanical material properties were based on the recommendations of the fire design code EN 1993-1-2 (CEN, 2005). In this code, the material properties are defined between $20^{\circ} \mathrm{C}$ and $1200^{\circ} \mathrm{C}$ for heating rates between 2 and $50^{\circ} \mathrm{C} / \mathrm{min}$. These material properties were derived for structures exposed to high temperatures for long times. Welding, on the other hand, is a much more short-term loading, but previous investigations (e.g. Kollár and Kövesdi, 2016; Krummenacker, 2011) have shown the applicability of the code for welding simulation purposes. In this case, phase transformations and microstructural changes are neglected - except for the temperature-dependent specific heat, which can still be applied for welding simulations. The rules in EN 1993-1-2 use reduction factors for considering the temperature-dependent Young's modulus, yield strength and stress-strain curves. It is important to note that, based on the results of the Ruoste project for HSS structures (RFCS, 2016), the same reduction factors can be used as those for NSS. This material model has a notable advantage: only the yield strength and Young's modulus need to be known at room temperature to describe the mechanical behaviour of the material at any elevated temperature. The required parameters are given in annex A of EN 1993-1-2 (CEN, 2005) to describe stress-strain curves.

It is convenient to deactivate the elements above the zerostrength temperature - which is taken as $1200^{\circ} \mathrm{C}-$ to avoid numerical instabilities due to small stiffness. 'Killing' the elements reduces stiffness radically while strains and stresses are zeroed out. An element is only activated again if its temperature has cooled below the critical value. The reference temperature of the deposited material has to be changed to the zero-strength temperature. This modelling technique is the socalled 'birth and death' method. In the case of thin plates $(t \leq 8 \mathrm{~mm})$, one weld pass per each weld is considered; otherwise, two weld passes are modelled. In the parametric studies, the following average heat input per unit length values were considered for one-pass and two-pass welding cases: $3.38 \mathrm{~kJ} / \mathrm{cm} \quad(t=4 \mathrm{~mm}), \quad 4.46 \mathrm{~kJ} / \mathrm{cm} \quad(t=5 \mathrm{~mm}), 4.84 \mathrm{~kJ} / \mathrm{cm}$ $(t=6 \mathrm{~mm}), 6.76 \mathrm{~kJ} / \mathrm{cm}(t=8 \mathrm{~mm}), 5.38 \mathrm{~kJ} / \mathrm{cm}$ and $13.1 \mathrm{~kJ} / \mathrm{cm}$ $(t=12 \mathrm{~mm}), \quad 13.1 \mathrm{~kJ} / \mathrm{cm}$ and $23.0 \mathrm{~kJ} / \mathrm{cm} \quad(t=16 \mathrm{~mm})$. In the SteelBeam project (BME, 2016), the effect of modelled specimen length and weld path numbers on the residual stress distributions were also investigated. Based on the results, it was concluded that the minimal model length should be around $2 b-2 \cdot 5 b$ to simulate the quasi-steady residual stress distribution in the middle cross-section. Therefore model lengths between $800-1500 \mathrm{~mm}$ are typically applied, depending on the b/t ratio.

4.3 Observed tendencies of residual stress distribution Verification of the thermo-mechanical model was completed by comparing the numerical and experimental longitudinal residual stresses of specimen $150 \times 6$ made of S460 steel grade. Figure 7 shows a comparison of the measured and computed residual stresses for one quarter of the specimen, together with the layout of the applied strain gauges.

The horizontal axis in Figure 7(a) indicates the position of the strain gauges while the vertical axis shows the longitudinal residual stresses. The vertical dashed line at $75 \mathrm{~mm}$ indicates the corner of the specimen. As shown in the figure, the experimental and numerical results were in good agreement and 


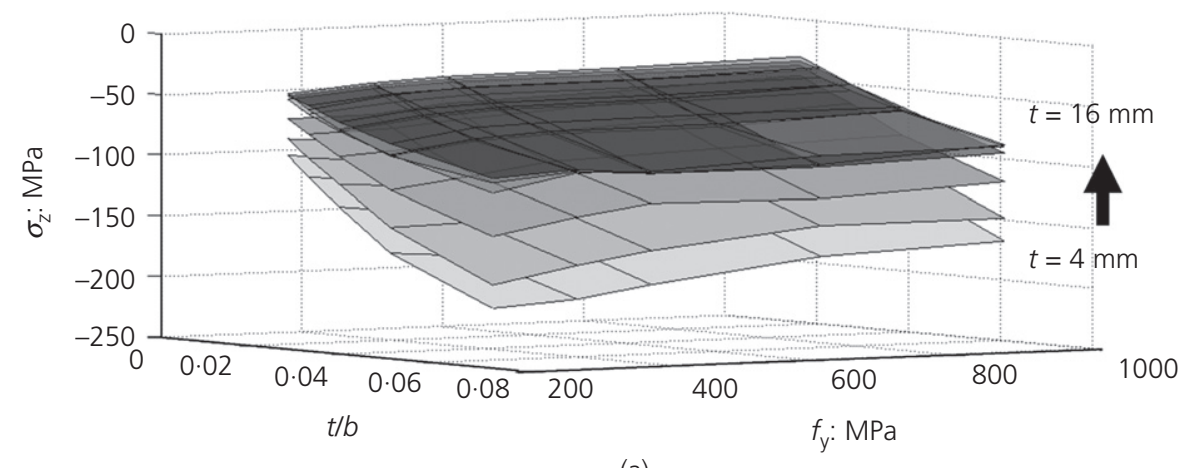

(a)

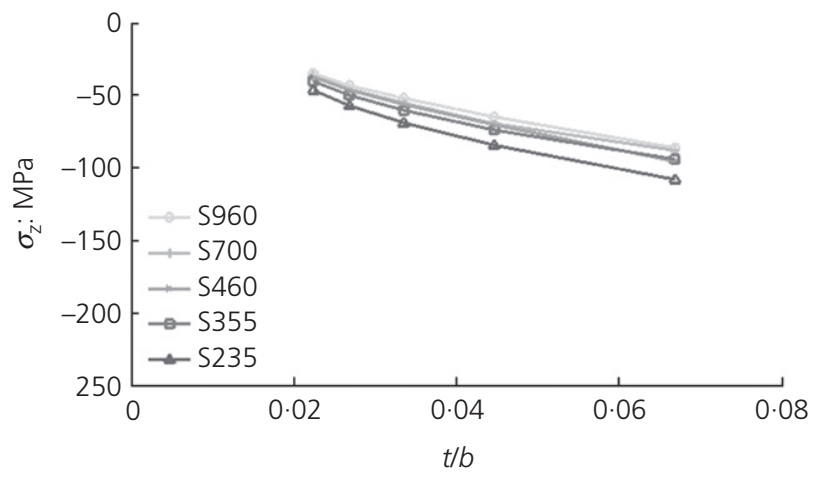

(b)

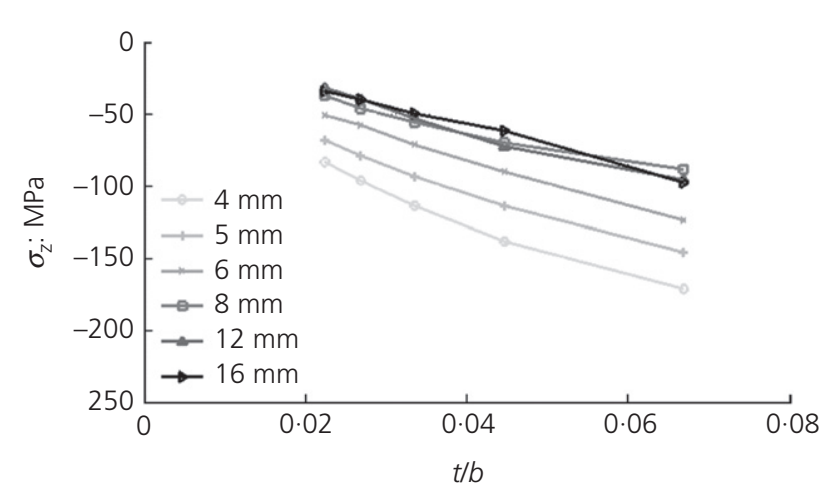

(c)

Figure 8. CRSs depending on: (a) plate thickness, b/t ratio and $f_{y}$; (b) yield strength; (c) plate thickness

the numerical model was thus considered to be valid for further application.

Through the parametric study, the effect of $b / t$ and $f_{\mathrm{y}}$ on the CRSs were determined; the results are presented in Figure 8. The observed tendencies are shown for a constant plate thickness by varying the $b / t$ ratio and the applied yield strength. The same parametric study was also executed for a constant steel grade by varying the thickness and the $b / t$ ratio of the specimen. Based on the numerical simulations, it can be concluded that the numerical results showed the same trends as observed in the experimental data (Figure 4). The magnitude of the CRSs increased with an increase in $t / b$ ratio for a constant plate thickness, and the tendency was different for different plate thicknesses. The results of the numerical study also confirmed the observation regarding the maximum compressive stress (i.e. the maximum compressive stress does not increase as the yield strength of the material increases).

These results provide important conclusions for developing design residual stress models. The numerical results showed that the CRSs in the panels were between $0.03 f_{\mathrm{y}}$ and $0.80 f_{\mathrm{y}}$ depending on the plate thickness, width-to-thickness ratio and yield strength, while the maximum TRSs reached the yield strength in all cases. The current standards generally give a fixed ratio; for example, in the ECCS (1976) residual stress model, CRSs are taken as $0 \cdot 13 f_{\mathrm{y}}$ or $0 \cdot 29 f_{\mathrm{y}}$ depending on the cross-section profile and manufacturing process. The numerical results obtained in this study prove that a higher yield strength does not result in higher CRSs. This is an important observation for HSS structures because the load-carrying capacity (especially the global buckling resistance) can be significantly larger for HSS members compared with NSS structures.

\section{Conclusions}

Residual stress measurements and numerical simulations were carried out to investigate the residual stress distributions in HSS welded box section members. The investigation was carried out on welded square box sections and the longitudinal residual stress patterns of the analysed cross-sections were determined and evaluated. Based on the test results and numerical simulations, the following tendencies were observed.

- CRSs are highly influenced by the $b / t$ ratio of the cross-section.

- The effect of $b / t$ on CRSs depends on the plate thickness $(t)$.

- CRS magnitudes are independent of the yield strength.

- Maximum TRS values are equal to the yield strength for all the steel grades analysed in this work. 
These observations should be beneficial for the design of HSS structures because the load-carrying capacity (especially the global buckling resistance) can be significantly larger for HSS members compared with NSS structures.

\section{Acknowledgements}

The research leading to these results received funding from the European Community's Research Fund for Coal and Steel under grant agreement RFSR-CT-2012-00036 and from the SteelBeam Hungarian R\&D project under grant agreement PIAC_13-1-2013-0160. This financial support is gratefully acknowledged. This paper was also supported by the János Bolyai Research Scholarship of the Hungarian Academy of Sciences awarded to the third author.

\section{REFERENCES}

Ansys (2013) Ansys ${ }^{\circledR}$ v14.5. Ansys Inc., Canonsburg, PA, USA. Ban H, Shi G, Shi Y and Wang Y (2013a) Residual stress of 460MPa high strength steel welded box section-Experimental investigation and modelling. Thin-Walled Structures 64: 73-82, https://doi.org/ 10.1016/j.tws.2012.12.007.

Ban H, Shi G, Shi Y and Bradford MA (2013b) Experimental investigation of the overall buckling behaviour of $960 \mathrm{MPa}$ high strength steel columns. Journal of Constructional Steel Research 88: 256-266, https://doi.org/10.1016/j.jcsr.2013.05.015.

Bradac J (2013) Calibration of heat source model in numerical simulations of fusion welding. Machines, Technologies, Materials 11: 9-12.

BME (Budapest University of Technology and Economics) (2016) SteelBeam Project Research Report. Department of Structural Engineering, BME, Budapest, Hungary, R\&D project PIAC_13-1-2013-0160.

CDSSC (Code for Design of Steel Structures Committee) (2003) Application Construal of Code for Design of Steel Structures in China. China Planning Press, Beijing, China (in Chinese).

CEN (European Committee for Standardization) (2005) EN 1993-1-2:2005: Eurocode 3: Design of steel structures - part 1-2: general rules - structural fire design. CEN, Brussels, Belgium.

Clarin M (2004) High Strength Steel Local Buckling and Residual Stresses. Licentiate thesis, Luleå University of Technology, Luleå, Sweden.

Clarin M and Lagerqvist O (2005) Residual stresses in square hollow sections made of high strength steel. In Advances in Steel Structures: Proceedings of the Fourth International Conference on
Advances in Steel Structures. Elsevier, Amsterdam, the Netherlands, pp. 1577-1582.

ECCS (European Convention for Constructional Steelworks) (1976) Manual on Stability of Steel Structures: Part 2.2. Mechanical Properties and Residual Stresses, 2nd edn. ECCS, Brussels, Belgium.

Galambos TV (1998) Guide to Stability Design Criteria for Metal Structures, 5th edn. Wiley, New York, NY, USA.

Goldak JA and Akhlaghi M (2005) Computational Welding Mechanics. Springer Science+Business Media, New York, NY, USA.

Kollár D and Kövesdi B (2016) Experimental and numerical simulation of welded columns. Proceedings of 41st International Conference Zavarivanje - Welding 2016 - Opatija, Croatia (Bauer B and Garasic I (eds)). Hrvatsko Drustvo Za Tehniku Zavarivanja/ Croatian Welding Society, Zagreb, Croatia, pp. 123-132.

Krummenacker J (2011) Simulation of the Welding Process of Steel Tube Joints Made of S355 and S690. MSc thesis, École Polytechnique Fédérale de Lausanne, Lausanne, Switzerland.

Naeem Ullah D (2009) Expert System for Optimization of Welding Process of Thin Walled HSLA Steel Structures. PhD thesis, University of Engineering \& Technology Taxila, Taxila, Pakistan.

Nishino F, Ueda Y and Tall L (1967) Experimental investigation of the buckling of plates with residual stresses. In Test Methods for Compression Members. American Society for Testing and Materials, West Conshohocken, PA, USA, ASTM Special Technical Publication 419, pp. 12-30.

Pavlovčič L, Froschmeier B, Kuhlmann U and Beg D (2012) Finite element simulation of slender thin-walled box columns by implementing real initial conditions. Advances in Engineering Software 44(1): 63-74.

Rasmussen KJR and Hancock GJ (1992) Plate slenderness limits for high strength steel sections. Journal of Constructional Steel Research 23(1-3): 73-96.

RFCS (Research Fund for Coal and Steel) (2016) Ruoste: Rules on High-Strength Steel (Feldmann M (ed.)). Publications Office of the European Union, Luxembourg, RFSR-CT-2012-00036, Final report.

Usami T and Fukumoto Y (1982) Local and overall buckling of welded box columns. Journal of the Structural Division ASCE 108(3): $525-542$.

Usami T and Fukumoto Y (1984) Welded box compression members. Journal of Structural Engineering 110(10): 2457-2470.

Uy B (2001) Strength of short concrete filled high strength steel box columns. Journal of Constructional Steel Research 57(2): 113-134.

Wang YB, Li GQ and Chen SW (2012) The assessment of residual stresses in welded high strength steel box sections. Journal of Constructional Steel Research 76: 93-99, https://doi.org/10.1016/ j.jcsr.2012.03.025.

\section{How can you contribute?}

To discuss this paper, please email up to 500 words to the editor at journals@ice.org.uk. Your contribution will be forwarded to the author(s) for a reply and, if considered appropriate by the editorial board, it will be published as discussion in a future issue of the journal.

Proceedings journals rely entirely on contributions from the civil engineering profession (and allied disciplines). Information about how to submit your paper online is available at www.icevirtuallibrary.com/page/authors, where you will also find detailed author guidelines. 